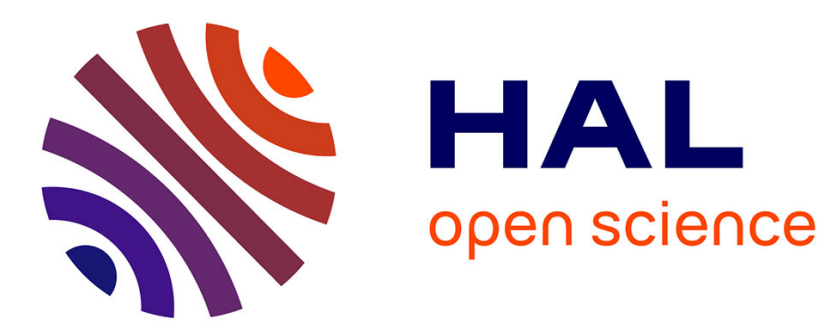

\title{
Evaluation of ice water content retrievals from cloud radar reflectivity and temperature using a large airborne in-situ microphysical database.
}

\author{
Alain Protat, Julien Delanoë, Dominique Bouniol, A. J. Heymsfield, A.
} Bansemer, P. Brown

\section{To cite this version:}

Alain Protat, Julien Delanoë, Dominique Bouniol, A. J. Heymsfield, A. Bansemer, et al.. Evaluation of ice water content retrievals from cloud radar reflectivity and temperature using a large airborne in-situ microphysical database.. Journal of Applied Meteorology, 2007, 46 (5), pp.557-572. 10.1175/JAM2488.1 . hal-00159835

\section{HAL Id: hal-00159835 \\ https://hal.science/hal-00159835}

Submitted on 25 Jan 2021

HAL is a multi-disciplinary open access archive for the deposit and dissemination of scientific research documents, whether they are published or not. The documents may come from teaching and research institutions in France or abroad, or from public or private research centers.
L'archive ouverte pluridisciplinaire HAL, est destinée au dépôt et à la diffusion de documents scientifiques de niveau recherche, publiés ou non, émanant des établissements d'enseignement et de recherche français ou étrangers, des laboratoires publics ou privés. 


\title{
Evaluation of Ice Water Content Retrievals from Cloud Radar Reflectivity and Temperature Using a Large Airborne In Situ Microphysical Database
}

\author{
A. Protat, J. Delanoë, and D. Bouniol \\ Centre d'étude des Environnements Terrestre et Planétaires, Vélizy, France \\ A. J. HeymsField And A. BANSEMER \\ National Center for Atmospheric Research,* Boulder, Colorado \\ P. BROWN \\ Met Office, Exeter, United Kingdom
}

(Manuscript received 12 December 2005, in final form 14 September 2006)

\begin{abstract}
The objective of this paper is to assess the performances of the proposed ice water content (IWC)-radar reflectivity $Z$ and IWC- $Z$-temperature $T$ relationships for accurate retrievals of IWC from radar in space or at ground-based sites, in the framework of the forthcoming CloudSat spaceborne radar, and of the European CloudNET and U.S. Atmospheric Radiation Measurement Program projects. For this purpose, a large airborne in situ microphysical database is used to perform a detailed error analysis of the IWC $-Z$ and IWC- $Z-T$ methods. This error analysis does not include the error resulting from the mass-dimension relationship assumed in these methods, although the expected magnitude of this error is bounded in the paper. First, this study reveals that the use of a single IWC- $Z$ relationship to estimate IWC at global scale would be feasible up to $-15 \mathrm{~dB} Z$, but for larger reflectivities (and therefore larger IWCs) different sets of relationships would have to be used for midlatitude and tropical ice clouds. New IWC $-Z$ and IWC $-Z-T$ relationships are then developed from the large aircraft database and by splitting this database into midlatitude and tropical subsets, and an error analysis is performed. For the IWC $-Z$ relationships, errors decrease roughly linearly from $+210 \% /-70 \%$ for IWC $=10^{-4} \mathrm{~g} \mathrm{~m}^{-3}$ to $+75 \% /-45 \%$ for IWC $=10^{-2} \mathrm{~g}$ $\mathrm{m}^{-3}$, are nearly constant $(+50 \% /-33 \%)$ for the intermediate IWCs $\left(0.03-1 \mathrm{~g} \mathrm{~m}^{-3}\right)$, and then linearly increase up to $+210 \% /-70 \%$ for the largest IWCs. The error curves have the same shape for the IWC $-Z-T$ relationships, with a general reduction of errors with respect to the IWC- $Z$ relationships. Comparisons with radar-lidar retrievals confirm these findings. The main improvement brought by the use of temperature as an additional constraint to the IWC retrieval is to reduce both the systematic overestimation and rms differences of the small IWCs (IWC $<0.01 \mathrm{~g} \mathrm{~m}^{-3}$ ). For the large IWCs, the use of temperature also results in a slight reduction of the rms differences but in a substantial reduction (by a factor of 2) of the systematic underestimation of the large IWCs, probably owing to a better account of the Mie effect when IWC- $Z$ relationships are stratified by temperature.
\end{abstract}

\section{Introduction}

Modeling studies clearly indicate that clouds play a major role in the earth radiation budget and hydrological cycle (e.g., Liou 1986; Ramanathan et al. 1989;

* The National Center for Atmospheric Research is sponsored by the National Science Foundation.

Corresponding author address: A. Protat, IPSL/CETP, 10-12 Avenue de l'Europe, 78140 Vélizy, France.

E-mail: alain.protat@cetp.ipsl.fr
Stephens et al. 1990). Although this point is widely recognized, the quantitative representation of clouds in climate models is still not adequate. For instance, different climate models still produce a very different ice water path, spanning an order of magnitude (Stephens et al. 2002). Clouds influence the shortwave and longwave radiation budget through scattering, absorption, and emission. The magnitude of these interactions between radiation and clouds primarily depends on cloud geometrical (cloud fraction, thickness, altitude) and microphysical properties (e.g., Stephens et al. 1990). Among the most critical cloud properties, the ice water

DOI: 10.1175/JAM2488.1 
content (IWC) and its vertical distribution inside clouds are of primary importance.

As a result, significant methodological progress has been achieved to derive more accurate estimates of IWC from the intensive use of synergetic combinations of instruments, both for operational weather forecasting and climate monitoring purposes. At regional and local scales, several single-sensor or multisensor approaches have indeed been developed to access accurate estimates of cloud IWC. All of these methods rely on the new generation of airborne and ground-based active (cloud radars, operating at 35 and $95 \mathrm{GHz}$, and backscatter and Raman lidars) and passive (infrared radiometers and imagers) remote sensing instruments. Among them, the radar-infrared radiometer (Matrosov 1997, 1999; Mace et al. 1998), radar-lidar (Intrieri et al. 1993; Donovan and van Lammeren 2001; Donovan et al. 2001; Wang and Sassen 2002; Tinel et al. 2005), and dual- or triple-wavelength radar (e.g., Sekelsky et al. 1999; Gaussiat et al. 2003) combinations have been extensively studied and are assumed to provide accurate estimates of IWC and effective radius, to within approximately $30 \%$, although further evaluations are still ongoing. The use of several radar wavelengths, however, is limited to clouds that contain particles that are large enough to Mie scatter at least one wavelength, and the methods that make use of infrared radiometers or lidars are limited to ice clouds that are not optically thick (optical depth of less than 3, roughly). Additional and sometimes significant problems with the synergetic methods arise from the fact that the cloud boundaries and sensed ice particles can be different at different wavelengths (Matrosov et al. 2002).

For these reasons, new single-sensor methods have been recently developed, mostly relying on cloud radar measurements [the whole Doppler spectrum (e.g., Babb et al. 1999), two or three moments of the Doppler spectrum (e.g., Matrosov et al. 2002; Protat et al. 2004), the radar reflectivity factor $Z$ and the temperature $T$ from an operational forecast model (Liu and Illingworth 2000, hereinafter LI00; Hogan et al. 2006a, hereinafter HO06), or the reflectivity factor only (e.g., Brown et al. 1995; Atlas et al. 1995; Heymsfield and Platt 1984; Liao and Sassen 1994; LI00)]. The two latest types of methods, which will be referred to as the IWC $-Z$ and IWC- $Z-T$ methods in the following, are particularly attractive in the perspective of the forthcoming launch of the first cloud radar in space ("CloudSat"; Stephens et al. 2002), as part of the constellation of satellites named the A-Train. This spaceborne cloud radar will provide a global coverage of reflectivity, from which the cloud properties could potentially be retrieved and used to provide observational constraints to operational models (e.g., Janiskova et al. 2002) in a simple and computationally efficient manner using the IWC $-Z$ and/or IWC- $Z-T$ methods (CloudSat is not a Doppler radar, and therefore the methods using Doppler velocities cannot be used).

The objective of this paper is to investigate in detail the performances that can be expected from the IWC $-Z$ and IWC $-Z-T$ methods. The motivation for this study is that the different relationships have been estimated in all cases from a limited set of airborne in situ microphysical measurements, which could have the effect of limiting the applicability of the different relationships in the literature to the geographical location at which they have been derived. Note, however, that this error analysis does not include the potential errors arising from the assumption of a mass-dimension relationship, although this represents a potentially significant error, as will be discussed later. The magnitude of this error is nevertheless bounded in the paper by using different mass-dimension assumptions. Because the objective is now to apply such methods for all types of ice clouds at global scale in the framework of CloudSat or at several ground-based radar sites in the framework of the European "CloudNET" (Illingworth et al. 2007) and the U.S. Atmospheric Radiation Measurement Program (ARM) projects, the degree of generality of such relationships had to be assessed. In this paper we make use of a large airborne in situ microphysical database gathered for the investigation of the stability of the normalized ice particle size distribution (Delanoë et al. 2005) to perform a detailed error analysis of the IWC $-Z$ and IWC $-Z-T$ methods and to answer the following questions: Do the IWC $-Z$ and IWC $-Z-T$ relationships proposed in the literature still hold when a large in situ microphysical database is used; that is, are these relationships applicable at global scale? Do the IWC $-Z$ and IWC- $Z-T$ relationships depend on geolocation (i.e., midlatitude vs Tropics)? By how much and in which IWC range does the IWC- $Z-T$ method outperform the IWC $-Z$ method?

The aircraft in situ database is briefly described in section 2, as well as the calculation of IWC and $Z$ at different wavelengths from the in situ microphysical data. The errors arising from the IWC $-Z$ relationships of LI00, as well as from new IWC- $Z$ relationships derived in the current paper from the in situ aircraft database, are analyzed in section 3 . The same error analysis is then performed for the IWC- $Z-T$ relationships in section 4. A more quantitative evaluation of the IWC estimates from these IWC- $Z$ and IWC- $Z-T$ relationships is then conducted in section 5 from comparisons with a more elaborate radar-lidar retrieval method us- 
ing both lidar backscatter and radar reflectivity as inputs. Conclusions are given in section 6 .

\section{Description of the airborne in situ microphysical database}

As discussed in the introduction, a large statistical microphysical database including both midlatitude and tropical field campaigns has been gathered in a previous study, the purpose of which was to investigate the stability in shape of the normalized ice particle size distribution (Delanoë et al. 2005). The construction of this large database offers the unique opportunity to evaluate the statistical significance of the IWC- $Z$ and IWC $-Z-T$ relationships proposed in the literature as applied to a much larger in situ aircraft database than that used to derive these relationships. For instance, in LI00, the statistical relationships for midlatitudes are derived from the European Cloud and Radiation Experiment (EUCREX) dataset only, but is this dataset representative of the natural scatter of IWC as a function of $Z$ ?

The IWC errors in the current paper are characterized in terms of the root-mean-square (rms) difference and mean difference in IWC classes between $\log _{10}$ (IWC) calculated directly from the particle size distributions and $\log _{10}$ (IWC) calculated using the IWC $-Z$ or IWC $-Z-T$ relationships.

The particle size distribution $N(D)$ is provided by airborne Particle Measuring Systems, Inc., two-dimensional cloud (2D-C) and two-dimensional precipitation (2D-P) microphysical optical array probes. Shadow images of cloud particles are in size ranges between 30 and $800 \mu \mathrm{m}$ for the 2D-C and between 200 and $6400 \mu \mathrm{m}$ for the 2D-P, with diameter intervals of 30 and $200 \mu \mathrm{m}$, respectively. Note, however, that sizes smaller than 100 $\mu \mathrm{m}$ measured by the $2 \mathrm{D}-\mathrm{C}$ probe are generally considered to be questionable, although corrections to these measurements have been proposed and validated (e.g., Shcherbakov et al. 2005). Recent field campaigns in the database also include Forward-Scattering Spectrometer Probe (FSSP) data, but not all of the experiments in the database do. The exploitation of these field campaigns has highlighted the bimodal nature of the particle size distribution of ice clouds, with the existence of a "small mode" characterized by sizes less than $100 \mu \mathrm{m}$. Note, however, that there is still a controversy regarding possible instrumental artifacts, and especially the artificial production of small particles by shattering of large ice crystals. We have chosen in this study not to include the available FSSP data, so as to keep the different field experiments comparable, but in the following we quantify the potential contribution of the FSSP particles to the total IWC. We have computed from the datasets of our database, which include the FSSP, 2D-C, and 2D-P sensors, the statistics of the relative rms difference between the IWC computed from 2D-C/2D-P only and the IWC computed from FSSP/2D-C/2D-P within different IWC bins. The total contribution varies slightly with IWC itself (not shown), but it ranges from around $10 \%-15 \%$ for IWC $<10^{-2} \mathrm{~g} \mathrm{~m}^{-3}$ to $4 \%-10 \%$ for IWC $>10^{-2} \mathrm{~g} \mathrm{~m}^{-3}$, which is in good agreement with the $10 \%$ value acknowledged, for instance, in Hogan and Illingworth (2003). It is noted that the effect on $Z$ is much less ( $1 \%$ at most) while the effect on visible extinction is very large, about $30 \%-40 \%$, as is also found in Gayet et al. (2002).

Another common difficulty with all of these sensors is the small collection area of the instrument, which implies that the inferred concentrations of the largest particles can be very noisy because of the cumulative effects of their low concentrations and the small volume sample. This is why individual samples are always averaged over a given time period (5-10 s, typically) to minimize this effect.

The database used in this study includes midlatitude datasets and tropical datasets, a fact that makes it a fairly representative database for ice clouds in these regions. Note that in the near future new in situ aircraft databases will be available for polar regions [e.g., the Arctic Study of Tropospheric Aerosols, Clouds, and Radiation (ASTAR) project], which will eventually be added to the current study so as to describe ice clouds at global scale.

There are five midlatitude experiments. The 1998 Cloud Lidar and Radar Experiment (CLARE98) took place from 5 to 23 October 1998 at the Observatory of Chilbolton, Hampshire, United Kingdom. This campaign was devoted to the characterization of the microphysical, radiative, and dynamic properties of nonprecipitating clouds. The U.K. C-130 was performing the in situ microphysical documentation of clouds using the FSSP, 2D-C, and 2D-P probes. In this dataset, we extracted $1 \mathrm{~h} 30 \mathrm{~min}$ of prefrontal ice cloud data.

The 1999 Clouds by Ground-Based and Airborne Radar and Lidar (CARL99) was held in Palaiseau, France, in April-May of 1999. This campaign was devoted to the investigation of the ice cloud properties and involved ground-based lidar, radar, and radiometry measurements as well as in situ validation measurements from aircraft. The Merlin IV aircraft from MétéoFrance was carrying the set of in situ microphysical probes from GKSS (FSSP, 2D-C, and 2D-P). This dataset corresponds to $2 \mathrm{~h} 10 \mathrm{~min}$ of cirrus observations.

ARM intensive airborne microphysical observations above the Southern Great Plains (SGP) site were carried out in 2000. The scientific objectives of these flights 
were to improve cloud and radiative models and parameterizations and, thereby, the performance of atmospheric general circulation models used for climate research. Four days in March of 2000, including Lagrangian spiral descents, are included in our database. This corresponds to $15 \mathrm{~h} 35 \mathrm{~min}$ of observations in a large variety of ice clouds.

EUCREX was a program focused on the earth radiation budget and climate change, starting in 1991 and continuing through 1995. A principal aim of EUCREX was to improve our knowledge of the physical processes that determine the radiative transfer properties of cloud fields. Airborne in situ microphysical measurements were collected using the 2D-C and 2D-P probes on board the U.K. C-130 research aircraft off the Scottish coast. In our database, these datasets correspond to approximately $20 \mathrm{~h}$ of cirrus data. This dataset is used in LI00 and HO06 to derive their IWC- $Z-T$ relationships.

The Fronts and Atlantic Storm-Track Experiment (FASTEX) took place in January-February of 1997 off the Irish coast over the North Atlantic Ocean. This international campaign was devoted to the investigation of multiscale processes associated with the mature stage of frontal cyclones developing in the trailing part of midlatitude fronts. Ten flights of the U.K. C-130 aircraft instrumented with the 2D-C and 2D-P sensors have been performed in the ice part of frontal cyclones, corresponding to $40 \mathrm{~h}$ of data in our database.

The two tropical experiments are less numerous but correspond to a fairly large number of flight hours, comparable to the number of midlatitude hours. The first experiment, the Central Equatorial Pacific Experiment (CEPEX), was conducted between 7 March and 5 April 1993 around the Solomon Islands, north of Australia. Of the 108 flight hours performed by the Learjet aircraft during CEPEX, three flights including 2D-C and $2 \mathrm{P}-\mathrm{P}$ probes were designed to measure the vertical and horizontal structure of the microphysical properties within mesoscale convective anvils and cirrus clouds. The CEPEX dataset corresponds to $34 \mathrm{~h}$ of tropical ice clouds, with temperatures ranging from $-65^{\circ}$ to $-10^{\circ} \mathrm{C}$. This dataset is that used together with the EUCREX dataset in LI00 to estimate a midlatitude/Tropics variability of IWC less than $25 \%$ when using the IWC- $Z-T$ relationships.

The Cirrus Regional Study of Tropical Anvils and Cirrus Layers (CRYSTAL) Florida Area Cirrus Experiment (FACE), the second tropical experiment, is a recent measurement campaign designed to investigate tropical cirrus cloud physical properties and formation processes. It took place in July of 2002 around Florida. Several aircraft were involved for in situ and remote sensing of ice crystals. Among these aircraft, the Cessna
Citation II aircraft of the University of North Dakota carried a state-of-the-art set of in situ microphysical instruments [2D-C probes, a continuous-flow diffusion chamber, a cloud-integrating nephelometer, a cloud particle imager, and a high-volume precipitation spectrometer (HVPS; 0.1-6-mm size range, 200- $\mu \mathrm{m}$ resolution)] but not the 2D-P probe used in our analysis for all of the other experiments. Spectra used in our study have therefore been constructed using a combination of the 2D-C and HVPS. This extensive dataset corresponds to $41 \mathrm{~h}$ of tropical ice clouds.

To perform the error analysis of IWC estimates from the IWC $-Z$ and IWC $-Z-T$ methods, we have computed the radar reflectivity factor at 35 and $95 \mathrm{GHz}$ (denoted as $Z_{35}$ and $Z_{95}$ in the following) and the IWC from all the particle size distributions included in the database. In the following, $Z$ will refer to radar reflectivities measured in millimeters to the sixth power divided by meters cubed $\left(\mathrm{mm}^{6} \mathrm{~m}^{-3}\right)$ and $\mathrm{ZdB}$ will refer to the radar reflectivities in reflectivity decibels $(\mathrm{dB} Z)$, that is, $\mathrm{ZdB}=10 \log _{10}(Z)$ :

$$
Z=\frac{\lambda^{4}}{\left|K_{w}\right|^{2} \pi^{5}} 10^{18} \int N(D) \sigma_{\mathrm{bsc}}(\rho, D, \lambda) d D,
$$

where $D$ is the maximum dimension, $\left|K_{w}\right|^{2}=0.93$ at 3 $\mathrm{GHz}, \sigma_{\mathrm{bsc}}$ is the Mie backscattering coefficient, $\rho$ is the ice particle density, and $\lambda$ is the wavelength. For the Mie calculations, we have used the spherical assumption for size, with the maximum dimension measured by the probes as the diameter of the spheres, but we corrected the refractive index assuming a given density of the ice particles instead of taking the density of solid ice, following the approach proposed by Oguchi (1983). This "fractional" refractive index is

$$
\varepsilon_{f}=\frac{2 f\left(\frac{\varepsilon_{i}-1}{\varepsilon_{i}+2}\right)+1}{1-f\left(\frac{\varepsilon_{i}-1}{\varepsilon_{i}+2}\right)},
$$

where $f=\rho(D) / \rho_{i}$ is the fraction of ice in the volume, $\rho(D)$ is the density of the ice particles assumed for the calculation, and $\rho_{i}$ is the density of solid ice. The same density-diameter relationship as that used in LI00 and HO06 has been considered, which is the Brown and Francis (1995)-Locatelli and Hobbs (1974) "aggregates of unrimed bullets, columns and side planes" relationship widely used in the literature $\left[\rho(D)=0.07 D(\mathrm{~cm})^{-1.1}\right]$. This implies that the error analyses in sections 3 and 4 do not include the errors arising from the use in IWC- $Z$ and IWC- $Z-T$ methods of a single density-diameter relationship for all ice clouds, which is also the case in all papers in the literature that address such relationships. Note that the use 
of a single mean density-diameter relationship for midlatitude and tropical ice clouds is obviously not a negligible source of error though, because the analysis of recent aircraft observations (Heymsfield et al. 2004) clearly shows that mean effective densities are larger for midlatitude ice clouds than for tropical ice clouds for the same size distribution slope parameters. Therefore, in section 4, the magnitude of this potential error is discussed and quantified using different particle habits. Note that the magnitude of this error is being investigated more thoroughly in an intercomparison exercise using blind-test vertical profiles of measured IWC and $Z$ in the frame of CloudSat that will soon be published (A. Heymsfield 2006, unpublished manuscript).

\section{Error analysis of IWC estimates from IWC-Z relationships}

Very different IWC- $Z$ relationships can be found in the literature (e.g., Brown et al. 1995; Atlas et al. 1995; Heymsfield and Platt 1984; Liao and Sassen 1994), which, according to the review by Matrosov (1997), suggests that the mean IWC predicted from these relationships can vary by 1.5 orders of magnitude. However, LI00 have highlighted that these large differences between previously reported $I W C-Z$ relationships could be essentially explained by the different radar wavelengths considered and the different assumptions made to relate particle mass and size. Indeed, when assuming the same mass-size relationship and making the calculations at the same wavelength, the differences in IWC computed from the different IWC- $Z$ relationships are substantially reduced in variability, down to $30 \%$, which, according to the authors, is mostly due to the departures from exponentiality of the particle size distribution. It is noteworthy, though, that additional sources of error are not included in this estimate, such as the assumption of a single ice density-diameter relationship and the fact that the database from which the relationships have been derived and the associated errors analyzed might be of limited statistical significance for some applications. LI00 finally propose somewhat "unified" IWC relationships at 35 and $95 \mathrm{GHz}$ derived from the tropical CEPEX and midlatitude EUCREX datasets, which are believed to produce IWC estimates with fractional errors of $+100 \% /-50 \%$, which is a level that corresponds to a mean rms difference in $\log _{10}$ (IWC) of 0.3 . These will be taken in the current paper as references for the different IWC- $Z$ relationships available in the literature:

$$
\begin{gathered}
\text { IWC }=0.097 Z_{35}^{0.590} \text { and } \\
\text { IWC }=0.137 Z_{95}^{0.643},
\end{gathered}
$$

where IWC is in grams per meter cubed $\left(\mathrm{g} \mathrm{m}^{-3}\right)$ and $\mathrm{Z}_{35 / 95}$ is in millimeters to the sixth power divided by meters cubed $\left(\mathrm{mm}^{6} \mathrm{~m}^{-3}\right)$. From the database described in the previous section, we have also derived such relationships at 35 and $95 \mathrm{GHz}$ using exactly the same method as that of LI00 for both the whole database ("global" relationships) and the midlatitude and tropical subsets of the in situ microphysical database (fit to the linear mean IWC computed in 5-dB reflectivity ranges):

$$
\begin{aligned}
\text { IWC } & =0.090 Z_{35}^{0.580}(\text { global; } 35 \mathrm{GHz}), \\
\mathrm{IWC} & =0.149 Z_{95}^{0.681}(\text { global; } 95 \mathrm{GHz}), \\
\mathrm{IWC} & =0.082 Z_{35}^{0.554}(\text { midlatitude; } 35 \mathrm{GHz}), \\
\mathrm{IWC} & =0.132 Z_{95}^{0.670}(\text { midlatitude; } 95 \mathrm{GHz}), \\
\mathrm{IWC} & =0.103 Z_{35}^{0.600}(\text { Tropics; } 35 \mathrm{GHz}), \text { and } \\
\mathrm{IWC} & =0.198 Z_{95}^{0.701}(\text { Tropics; } 95 \mathrm{GHz}) .
\end{aligned}
$$

These different relationships are displayed for the two radar frequencies in Fig. 1, for both the whole database (Fig. 1a) and the midlatitude (Fig. 1b) and tropical (Fig. 1c) subsets of the database. From these figures it is clearly apparent that for both the whole database and subsets and for the two radar frequencies, the overall agreement between the LI00 and the (3)-(8) IWC-Z relationships derived in the current paper is very good, with the largest differences being observed at $95 \mathrm{GHz}$ for the tropical subset. This latter result is consistent with the fact that the LI00 relationships have been obtained with a midlatitude dataset. This overall agreement is also clear from the very comparable mean rms differences reported in Table 1, for both the whole database and the midlatitude and tropical subsets. It is observed, as expected, that the new relationships in (3)-(8) systematically produce smaller rms differences than do the LI00 relationships, but the differences are fairly small, both globally and for the midlatitude and tropical subsets. These rms differences range from 0.237 to 0.295 , which corresponds to fractional errors of $+75 \% /-43 \%$ and $+97 \% /-49 \%$, respectively. These errors are slightly smaller than the $+100 \% /-50 \%$ fractional error acknowledged in LI00. If we assume that the dataset used in LI00 is statistically representative of the natural variability of IWC as a function of $Z$, then the rms difference obtained with (3)-(8) should decrease by a factor $N^{1 / 2}$ when using our much larger database, where $N$ is the number of additional points in our database as compared with LI00. As seen in Table 1 , the errors are indeed slightly smaller than those found in LI00 but are not much smaller. This result could be due to different ways to calculate the errors in 

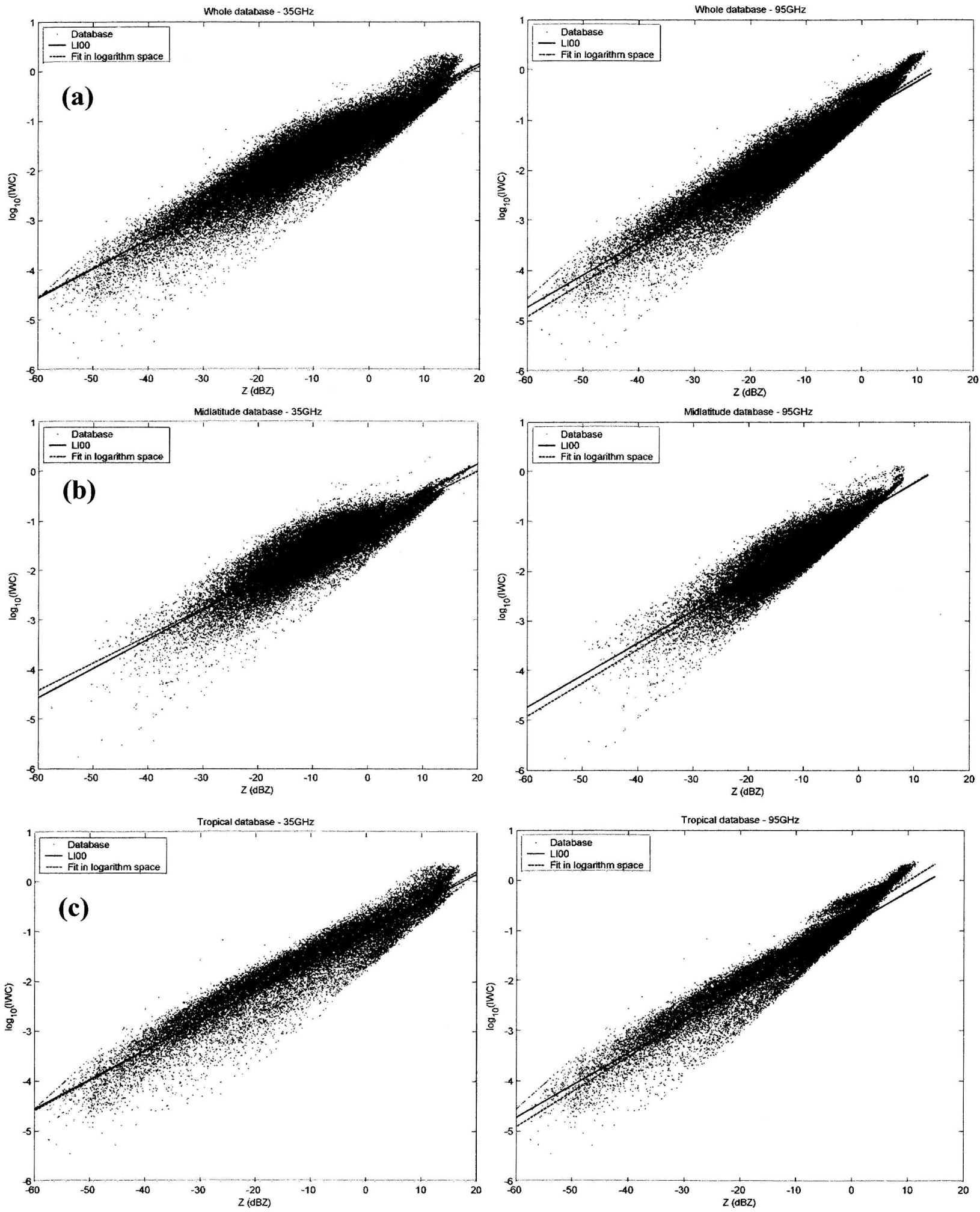

FIG. 1. IWC as a function of $Z$ at (left) 35 and (right) $95 \mathrm{GHz}$ for (a) the whole aircraft in situ database, (b) the midlatitude subset of the database, and (c) the tropical subset of the database. The solid lines are the LI00 relationships, and the dashed lines are the IWC relationships derived from a least squares fit in logarithmic space ("log fit"). 
TABLE 1. Mean rms difference between $\log$ (IWC) computed from the true particle size distributions and a mass-dimension assumption (the reference) and $\log (\mathrm{IWC})$ computed from the IWC- $Z$ relationships at 35 and $95 \mathrm{GHz}$ from LI00 and from the current analysis. This error analysis is conducted using the whole database, the midlatitude subset, or the tropical subset. The corresponding fractional error on IWC is also indicated. The error analysis using EUCREX is also reported to allow comparison with LI00.

Radar frequency

\begin{tabular}{lll}
\multicolumn{1}{c}{$(\mathrm{GHz})$} & \multicolumn{1}{c}{ LI00's IWC-Z } & \multicolumn{1}{c}{ Our IWC-Z } \\
\hline 35, global & $0.285(+93 \% /-48 \%)$ & $0.283(+91 \% /-48 \%)$ \\
95, global & $0.255(+80 \% /-44 \%)$ & $0.252(+78 \% /-44 \%)$ \\
35, midlatitude & $0.280(+91 \% /-48 \%)$ & $0.275(+88 \% /-47 \%)$ \\
95, midlatitude & $0.242(+75 \% /-43 \%)$ & $0.237(+73 \% /-42 \%)$ \\
35, Tropics & $0.295(+97 \% /-49 \%)$ & $0.294(+97 \% /-49 \%)$ \\
95, Tropics & $0.281(+91 \% /-48 \%)$ & $0.256(+80 \% /-44 \%)$ \\
35, EUCREX & $0.329(+113 \% /-53 \%)$ & $0.307(+103 \% /-51 \%)$ \\
95, EUCREX & $0.282(+91 \% /-48 \%)$ & $0.276(+88 \% /-47 \%)$ \\
\hline
\end{tabular}

the different publications, and therefore we have redone the same error analysis taking only the EUCREX dataset (which is the dataset used in LI00 and HO06) so as to compare the rms differences obtained with the EUCREX dataset with those from the whole database. This analysis of errors from EUCREX only is also reported in Table 1. When comparing the errors in Table 1 for the whole database and EUCREX, it appears that the rms differences are about $10 \%$ larger when only EUCREX is used but again are not much larger. This result may indicate that caution should be exercised when using a single dataset such as EUCREX to derive statistical relationships, although the LI00 relationships are in this particular case almost as accurate as the (3)-(4) relationships.

The error characteristics are now analyzed more precisely within IWC classes (Fig. 2 at $35 \mathrm{GHz}$, and Fig. 3 at $95 \mathrm{GHz}$ ). When the whole database is used (Fig. 2a), the rms differences at $35 \mathrm{GHz}$ are largest for small IWCs, decreasing roughly linearly from $0.6(+300 \% /$ $-75 \%$ fractional error) for $\log _{10}$ (IWC) $=-4$ to 0.25 $(+75 \% /-45 \%)$ for $\log _{10}($ IWC $)=-2$. The rms errors then remain constant for $-2<\log _{10}$ (IWC) $<-0.8$. The minimum rms error of $0.18(+50 \% /-33 \%)$ is obtained for $\log _{10}(\mathrm{IWC})=-0.4\left(\mathrm{IWC}=0.4 \mathrm{~g} \mathrm{~m}^{-3}\right)$, and then for the large IWCs the errors linearly increase to reach $0.5(+210 \% /-70 \%)$ at $\log _{10}(\mathrm{IWC})=0.3$ (i.e., $\mathrm{IWC}=$ $\left.2 \mathrm{~g} \mathrm{~m}^{-3}\right)$. The error characteristics as a function of IWC are about the same for intermediate to large IWCs $\left[\log _{10}(\right.$ IWC) $>-2.5]$ when the midlatitude (Fig. 2b) and tropical (Fig. 2c) subsets are used. The main differences are for the smaller IWCs, with the errors for the midlatitude subset being much larger [0.7 at $\log _{10}($ IWC $)=-3.5$ instead of 0.5 for the whole data- base, which corresponds to a $+400 \% /-80 \%$ fractional error] and the errors for the tropical subset being much smaller $\left[180 \% /-65 \%\right.$ at $\log _{10}$ (IWC) $=-4$ instead of $+300 \% /-75 \%$ for the whole database]. It is noteworthy that the errors reported in Figs. 2 and 3 have characteristics as a function of IWC that are comparable to the findings of Hogan and Illingworth (1999) using EUCREX and CEPEX (their Figs. 3 and 4), with errors in our case being systematically smaller over the whole IWC range.

At $95 \mathrm{GHz}$ (Fig. 3), we only show the error analysis in IWC classes for the whole database, because the results are similar for the midlatitude and tropical subsets. At this frequency the error decreases linearly from 0.5 for IWC $=10^{-4} \mathrm{~g} \mathrm{~m}^{-3}(+210 \% /-70 \%)$ to a minimum of 0.18 for IWC $=0.1 \mathrm{~g} \mathrm{~m}^{-3}(+50 \% /-33 \%)$ and then increases again linearly up to $0.42(+160 \% /$ $-60 \%$ ) for IWC $=2 \mathrm{~g} \mathrm{~m}^{-3}$.

This large microphysical in situ database also offers the opportunity to evaluate the variability of IWC for a given reflectivity between midlatitude and tropical ice clouds. In LI00, IWC was found to be on average 30\% lower at midlatitudes than in the Tropics for the same reflectivity. Using the current microphysical in situ database, we have computed the mean IWCs with the midlatitude and tropical subsets (Fig. $4 a$ and $4 b$, respectively) and the relative mean difference between the midlatitude IWC and the tropical IWC (Fig. 4c) within 5-dBZ reflectivity classes at 35 and $95 \mathrm{GHz}$ and using the same density-diameter assumption for the midlatitude and tropical datasets (although note that this relationship could be different). From Fig. $4 c$ it appears that from -40 to $-15 \mathrm{dBZ}$ the tropical IWCs are generally $5 \%-10 \%$ larger than the midlatitude IWCs for a given reflectivity, whatever the radar frequency. Then the relative mean difference increases very rapidly from -15 to $5 \mathrm{dBZ}$, with tropical IWCs about $20 \%$ (40\%) larger than the midlatitude IWCs for a $35-\mathrm{GHz}(95$ $\mathrm{GHz})$ reflectivity of $-5 \mathrm{dBZ}$ and $60 \%(80 \%)$ larger than the midlatitude IWCs for a $35-\mathrm{GHz}(95 \mathrm{GHz})$ reflectivity of $+5 \mathrm{dBZ}$. The mean difference over the whole reflectivity range is $20 \%$ at $35 \mathrm{GHz}$ and $28.5 \%$ at $95 \mathrm{GHz}$, which is in good agreement with the $30 \%$ found globally in LI00. The distribution of the mean relative difference in IWC at midlatitudes and in the Tropics is, however, not uniform over the whole reflectivity range. The use of a single IWC $-Z$ relationship to estimate IWC at global scale would therefore be feasible up to $-15 \mathrm{~dB} Z$, but for larger reflectivities different sets of relationships must be used for midlatitude and tropical ice clouds. This is likely due to the fact that these two main geographical locations are broadly characterized by two archetypal types of cloud initiation: 
(a)

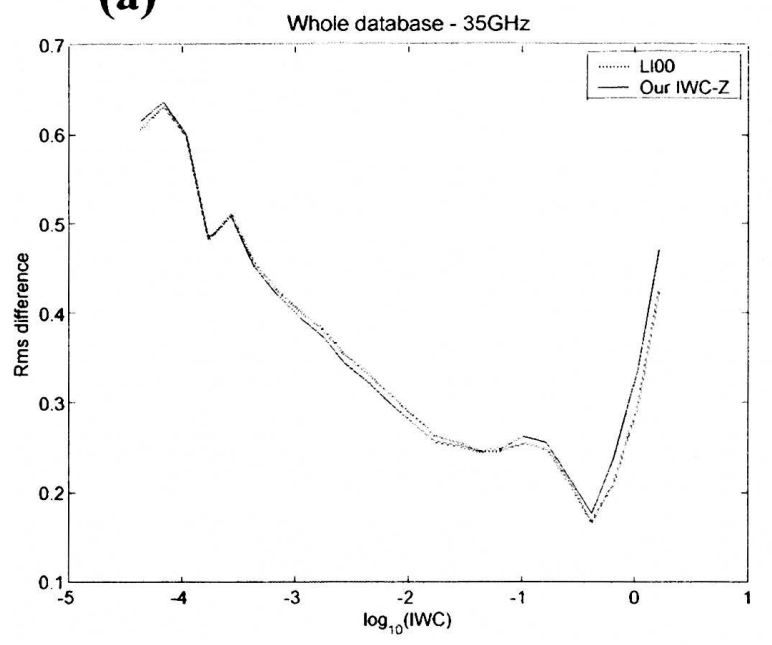

(b)

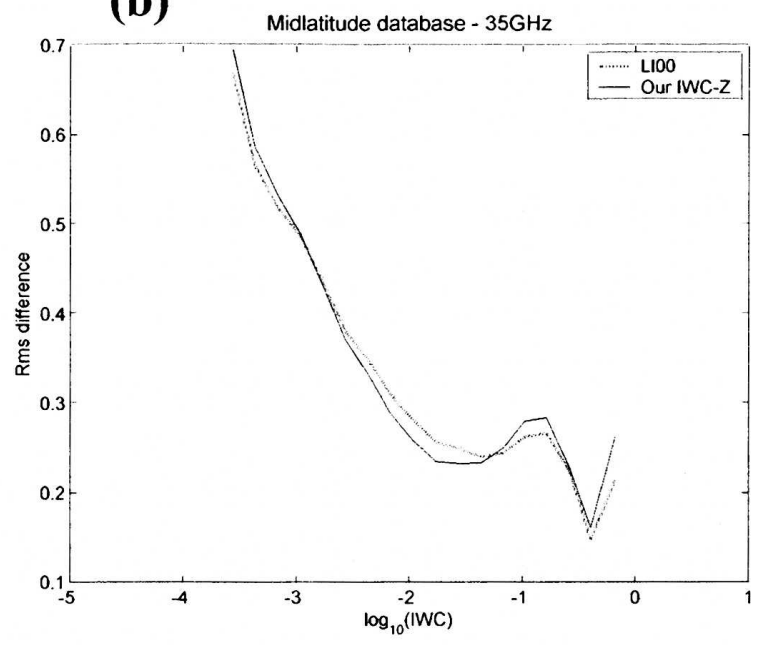

(c)

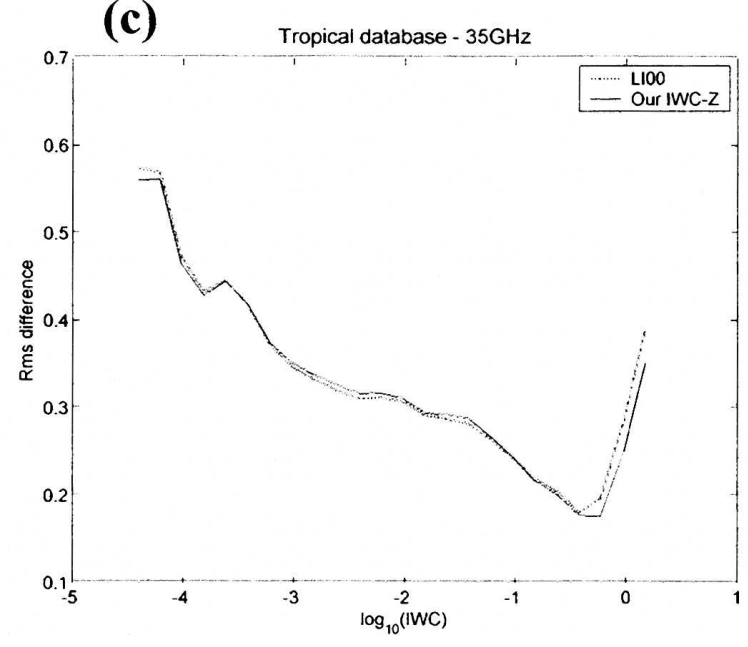

FIG. 2. Rms difference between the $\log$ (IWC) computed from the true particle size distributions and a mass-dimension assumption (the reference) and the $\log$ (IWC) computed from the LI00 relationship at $35 \mathrm{GHz}$ (dotted line) or the relationships derived at $35 \mathrm{GHz}$ in the current study (solid line) for (a) the whole database, (b) the midlatitude subset of the database, and (c) the tropical subset of the database.

the ice clouds generated by a large-scale uplift (mostly at midlatitudes) and the ice clouds triggered by convection (mostly in the Tropics). However, this is not a systematic rule; therefore, it would require a careful analysis of the datasets to conclude unambiguously. Such an analysis is beyond the scope of this paper.

\section{Error analysis of IWC estimates from IWC- $Z-T$ relationships}

The spread of IWC $-Z-T$ relationships in the literature is much less than that of the IWC- $Z$ relationships, because this approach has been only recently proposed by LI00, who demonstrated by using the EUCREX and CEPEX datasets that the incorporation of temperature as an additional constraint to the IWC $-Z$ relationships resulted in a substantially more accurate estimate of IWC. HO06 recently refined this analysis to produce smoother variations from a temperature class to the next. They also repeated the same analysis as that for IWC to develop $\alpha-Z-T$ relationships, where $\alpha$ is the visible extinction coefficient. Two sets of relationships have been derived by HO06, which have specific interests. The first set of IWC- $Z-T$ relationships corresponds to the so-called expected value for IWC, which is the expected best estimate of IWC:

$$
\begin{aligned}
\log _{10}(\mathrm{IWC})= & 0.000242 \mathrm{ZdB}_{35} T+0.0699 \mathrm{ZdB}_{35} \\
& -0.0186 T-1.63 \text { and } \\
\log _{10}(\mathrm{IWC})= & 0.000580 \mathrm{ZdB}_{95} T+0.0923 \mathrm{ZdB}_{95} \\
& -0.0071 T-0.99 .
\end{aligned}
$$




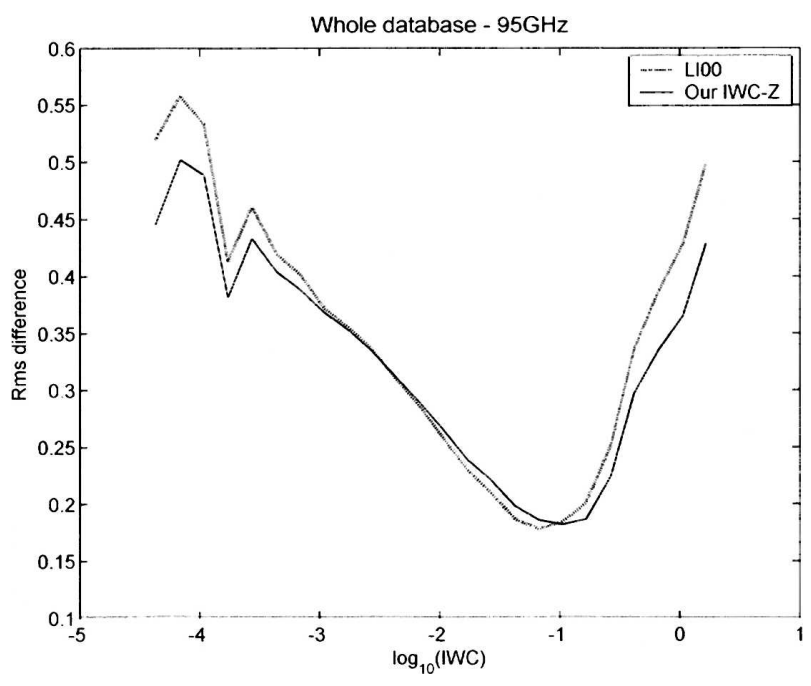

FIG. 3. Rms difference between the $\log$ (IWC) computed from the true particle size distributions and a mass-dimension assumption (the reference) and the $\log$ (IWC) computed from the LI00 relationship at $95 \mathrm{GHz}$ (dotted line) or the relationship derived at $95 \mathrm{GHz}$ in this study (solid line) for the whole database.

As for the IWC $-Z$ relationships, we have developed IWC- $Z-T$ relationships using the expected-value approach of HO06 (i.e., a fit to the linear mean IWCs computed in 5-dB reflectivity and $5^{\circ} \mathrm{C}$ temperature intervals), but using the whole database and then using the midlatitude and tropical subsets of the database. These relationships are readily comparable to (9) and (10):

$$
\begin{aligned}
\log _{10}(\mathrm{IWC})= & 0.000234 \mathrm{ZdB}_{35} T+0.0747 \mathrm{ZdB}_{35} \\
& -0.0111 T-1.41 \text { (global), } \\
\log _{10}(\mathrm{IWC})= & 0.000491 \mathrm{ZdB}_{95} T+0.0939 \mathrm{ZdB}_{95} \\
& -0.0023 T-0.84 \text { (global), } \\
\log _{10}(\mathrm{IWC})= & 0.000372 \mathrm{ZdB}_{35} T+0.0782 \mathrm{ZdB}_{35} \\
& -0.0153 T-1.54 \text { (midlatitude), } \\
\log _{10}(\mathrm{IWC})= & 0.000716 \mathrm{ZdB}_{95} T+0.0978 \mathrm{ZdB}_{95} \\
& -0.0016 T-0.87 \text { (midlatitude), } \\
\log _{10}(\mathrm{IWC})= & 0.000185 \mathrm{ZdB} 35+0.0735 \mathrm{ZdB}{ }_{35} \\
& -0.0091 T-1.31 \text { (Tropics), and } \\
\log _{10}(\mathrm{IWC})= & 0.000457 \mathrm{ZdB}_{95} T+0.0969 \mathrm{ZdB}{ }_{95} \\
& -0.0002 T-0.61 \text { (Tropics). }
\end{aligned}
$$

A second set of IWC $-Z-T$ relationships derived by HO06 produces an unbiased variance for IWC, which is not the objective in our paper. Therefore, in what follows only the expected-value approach is retained and discussed.

The mean rms differences are reported in Table 2 for the whole database and the midlatitude and tropical subsets. It is observed that the IWC- $Z-T$ relationships (11)-(16) systematically produce smaller rms differences than do the HO06 relationships, which is consistent with the fact that they have been derived using the database used to evaluate the errors, whereas the HO06 relationships had been obtained from a small subset. These rms differences range from 0.216 to 0.257 , which corresponds to fractional errors of $+65 \% /-40 \%$ and $+80 \% /-45 \%$, respectively. It is noteworthy that these mean errors are systematically smaller than the mean errors obtained in the previous section for the IWC- $Z$ relationships reported in Table 1 , which are readily comparable with Table 2 . More quantitative is that the rms differences obtained with the (11)-(16) IWC $-Z-T$ relationships are about $10 \%-15 \%$ smaller than those of the (3)-(8) IWC- $Z$ relationships.

The error characteristics are now analyzed within IWC classes (Fig. 5 at $35 \mathrm{GHz}$, and Fig. 6 at $95 \mathrm{GHz}$ ), as was done for the IWC- $Z$ methods. For sake of comparison, the error curves corresponding to the (3)-(8) IWC- $Z$ relationships are superimposed in Figs. 5 and 6. It is first obtained that the shape of the error curves as a function of IWC for the IWC- $Z-T$ relationships is similar in all cases to the shape of the error curve for the IWC $-Z$ relationships, with a general reduction of the error magnitudes. The (11)-(16) IWC- $Z-T$ relationships are generally those that produce the smallest errors at all IWCs. With the whole database (Fig. 5a), the rms differences at $35 \mathrm{GHz}$ are largest for small IWCs, as was the case with the IWC- $Z$ relationships, decreasing roughly linearly from $0.46(+190 \% /-65 \%$ fractional error) for $\log _{10}$ (IWC) $=-4$ to $0.23(+70 \% /$ $-40 \%)$ for $\log _{10}($ IWC $)=-2$. Then the rms errors remain constant for $-2<\log _{10}$ (IWC) $<-0.8$. The minimum rms error of $0.18(+50 \% /-33 \%)$ is obtained for $\log _{10}($ IWC $)=-0.4\left(\right.$ IWC $\left.=0.4 \mathrm{~g} \mathrm{~m}^{-3}\right)$. Then for the large IWCs the errors linearly increase to reach 0.38 $(+140 \% /-60 \%)$ at $\log _{10}(\mathrm{IWC})=0.3$ (i.e., $\mathrm{IWC}=2 \mathrm{~g}$ $\left.\mathrm{m}^{-3}\right)$. The error characteristics as a function of IWC are about the same when the midlatitude (Fig. 5b) and tropical (Fig. 5c) subsets are considered. The comparison in Fig. 5 between the rms differences associated with the 35-GHz IWC- $Z$ relationships (3), (5), and (7) and the $35-\mathrm{GHz}$ IWC- $Z-T$ relationships (11), (13), and (15) in IWC classes clearly demonstrates the considerable improvement brought by the use of temperature 

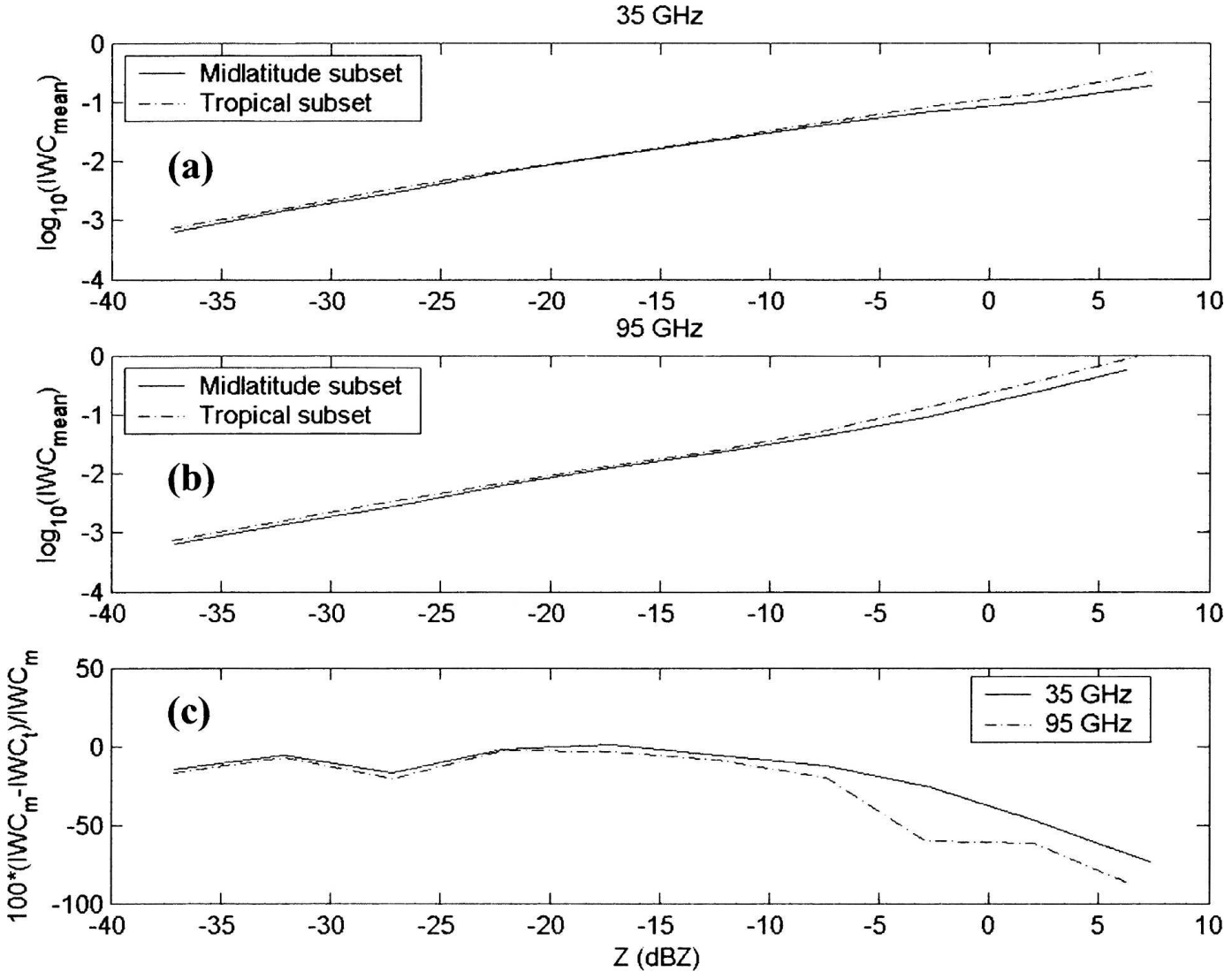

FIG. 4. Logarithm of the mean IWC in reflectivity classes at (a) 35 and (b) $95 \mathrm{GHz}$ for the midlatitude subset (solid line) and tropical subset (dot-dashed line) of the database. (c) Relative mean difference in ice water content between the midlatitude and tropical subsets as a function of reflectivity at 35 (solid line) and 95 (dot-dashed line) GHz.

as an additional constraint for the small IWCs $\left[\log _{10}\right.$ (IWC) $<-1.5$, or IWC $<0.03 \mathrm{~g} \mathrm{~m}^{-3}$; see Fig. 5]. This improvement is, however, much less obvious for the intermediate to large IWCs, both for the whole database and its midlatitude and tropical subsets.

At $95 \mathrm{GHz}$, both for the whole database (Fig. 6a) and its midlatitude (Fig. 6b) and tropical (Fig. 6c) subsets, the rms difference decreases linearly from 0.4 for IWC $=10^{-4} \mathrm{~g} \mathrm{~m}^{-3}(+150 \% /-60 \%)$ to a minimum of 0.18 for $\mathrm{IWC}=0.1 \mathrm{~g} \mathrm{~m}^{-3}(+50 \% /-33 \%)$, and then increases again linearly up to $0.3(+100 \% /-50 \%)$ for IWC $=2 \mathrm{~g} \mathrm{~m}^{-3}$. As at $35 \mathrm{GHz}$, the improvement brought by the use of temperature as an additional constraint to the IWC retrieval is significant for the small IWCs $\left[\log _{10}(\mathrm{IWC})<-1.5\right.$, or IWC $<0.03 \mathrm{~g} \mathrm{~m}^{-3}$; see Fig. 6]. However, contrary to the $35-\mathrm{GHz}$ case, the use of temperature also improves the IWC retrieval for the large IWCs $\left[\log _{10}(\mathrm{IWC})>-0.4\right.$, or IWC $\left.>0.4 \mathrm{~g} \mathrm{~m}^{-3}\right]$. This result is likely due to the fact that the Mie effects, which tend to produce strong departures from linearity of the $\log _{10}(\mathrm{IWC})-Z$ relationship at large IWCs (see the low quality of the fits at $95 \mathrm{GHz}$ on Fig. 1 for the large IWCs), are much more challenging to be accounted for in IWC- $Z$ relationships than when these relationships are stratified by temperature.

As discussed in section 2, these error statistics do not

TABLE 2. Mean rms difference between $\log$ (IWC) computed from the true particle size distributions and a mass-dimension assumption (the reference) and $\log$ (IWC) computed from the IWC $-Z-T$ relationships at 35 and $95 \mathrm{GHz}$ from $\mathrm{HO} 06$ and from this analysis. This error analysis is conducted using the whole database, the midlatitude subset, or the tropical subset. The corresponding fractional error on IWC is also indicated.

\begin{tabular}{lcc}
\hline \hline $\begin{array}{c}\text { Radar frequency } \\
(\text { GHz })\end{array}$ & HO06's IWC-Z & Our IWC-Z-T \\
\hline 35, global & $0.283(+91 \% /-48 \%)$ & $0.248(+77 \% /-43 \%)$ \\
95, global & $0.254(+80 \% /-44 \%)$ & $0.227(+69 \% /-41 \%)$ \\
35, midlatitude & $0.250(+78 \% /-44 \%)$ & $0.236(+73 \% /-42 \%)$ \\
95, midlatitude & $0.239(+73 \% /-42 \%)$ & $0.216(+64 \% /-39 \%)$ \\
35, Tropics & $0.344(+121 \% /-55 \%)$ & $0.257(+80 \% /-44 \%)$ \\
95, Tropics & $0.284(+92 \% /-48 \%)$ & $0.224(+67 \% /-40 \%)$ \\
\hline
\end{tabular}



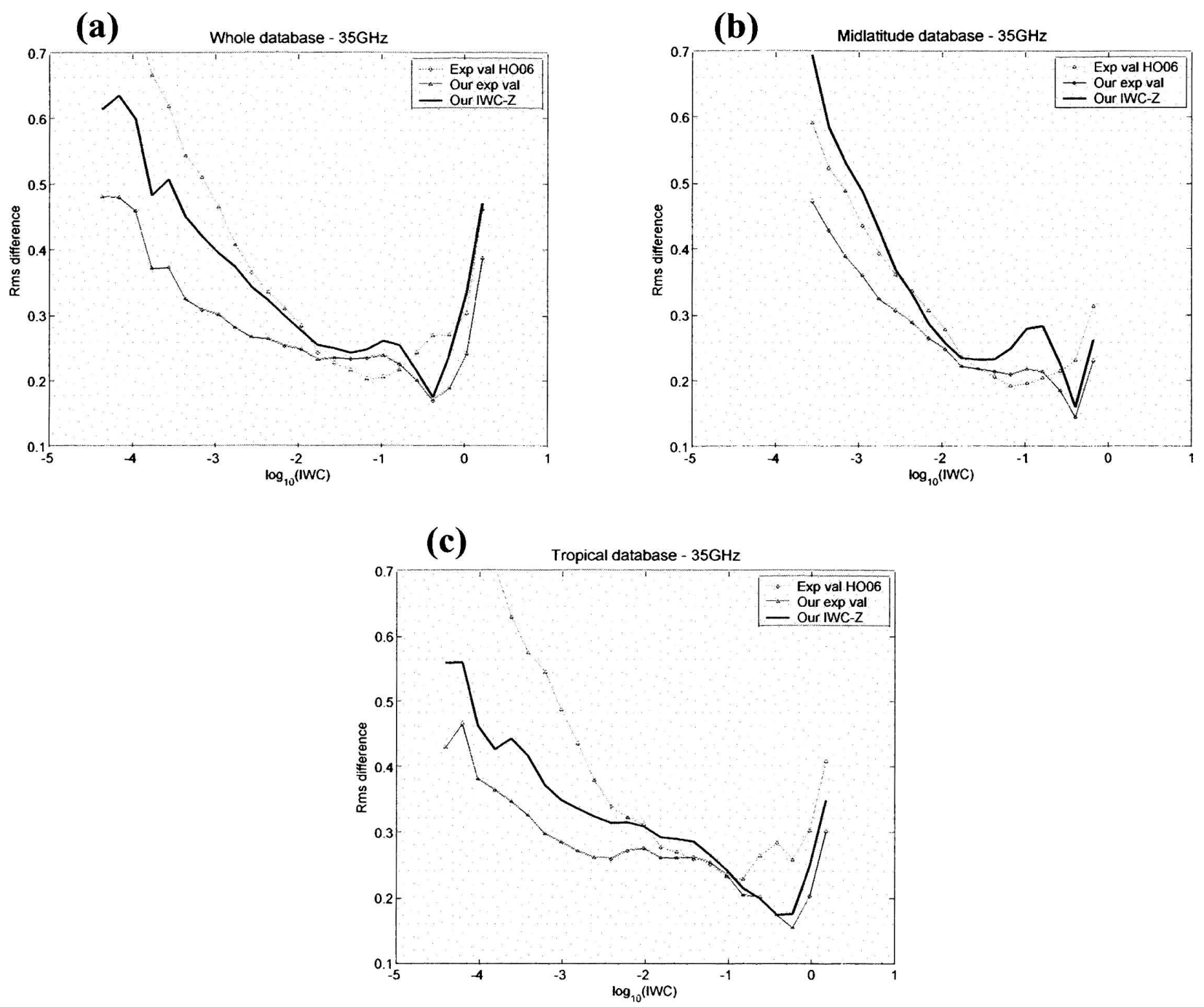

FIG. 5. Rms difference between the $\log$ (IWC) computed from the true particle size distributions and a mass-dimension assumption (the reference) and the $\log$ (IWC) computed at $35 \mathrm{GHz}$ from the IWC-Z-T expected-value relationships of HO06 (dotted line with circles), from the IWC- $Z-T$ expected value relationships (thin solid line with circles) and the IWC $-Z$ relationships (thick solid lines) derived in this study using (a) the whole database, (b) the midlatitude subset of the database, and (c) the tropical subset of the database.

include the errors resulting from the assumption of a single density-diameter relationship for all clouds. To estimate the magnitude of this error, we used the previous IWC- $Z-T$ relationships that had been obtained assuming the Brown and Francis (1995) aggregates, but applied them using three sets of reflectivity calculated using three typical particle habits in the literature for ice clouds: aggregates of side planes/columns/bullets, bullet rosettes, and hexagonal plates. We then computed the IWC error statistics using the IWCs calculated with the three previous particle habits as a reference. By doing this, we include both the errors of the IWC- $Z-T$ fits and the error on the assumption of an ice particle density. The result of this sensitivity test is shown in Fig. 7. This figure shows that there is a rela- tively constant increase of the errors over the whole IWC range. The largest errors are when bullet rosettes are considered. Overall, there is a $0.05-0.1$ increase in the rms errors on $\log$ (IWC), which is not negligible but is not extremely large. As discussed previously, this error will be quantified in a much more accurate manner using direct IWC measurements from the counterflow virtual impactor inlet during recent field projects.

When comparing rms differences, the systematic and random contributions to the total error are mixed. Presumably with temperature as an additional constraint a significant part of the error is random, whereas the IWC $-Z$ relationships tend to produce systematic overestimation of small IWCs and underestimation of the large IWCs. To check this, we have reported in Fig. 8 
(a)

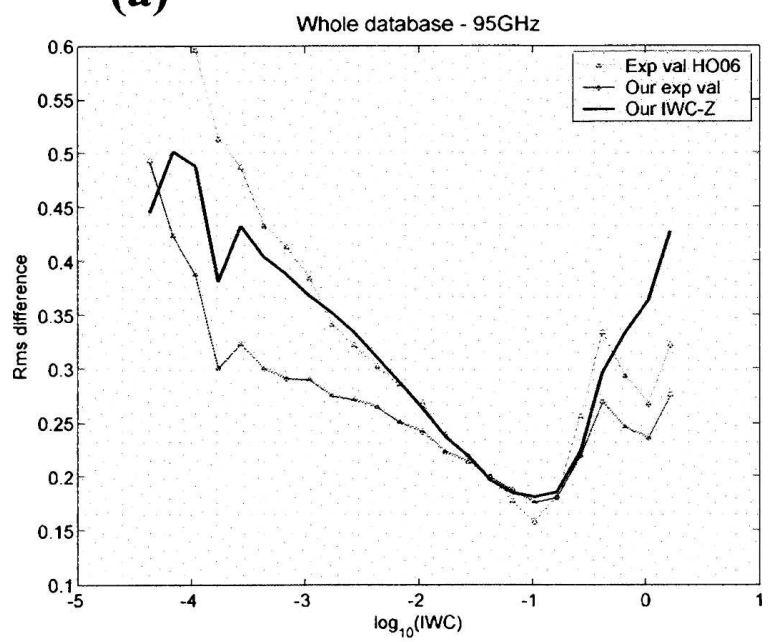

(b)

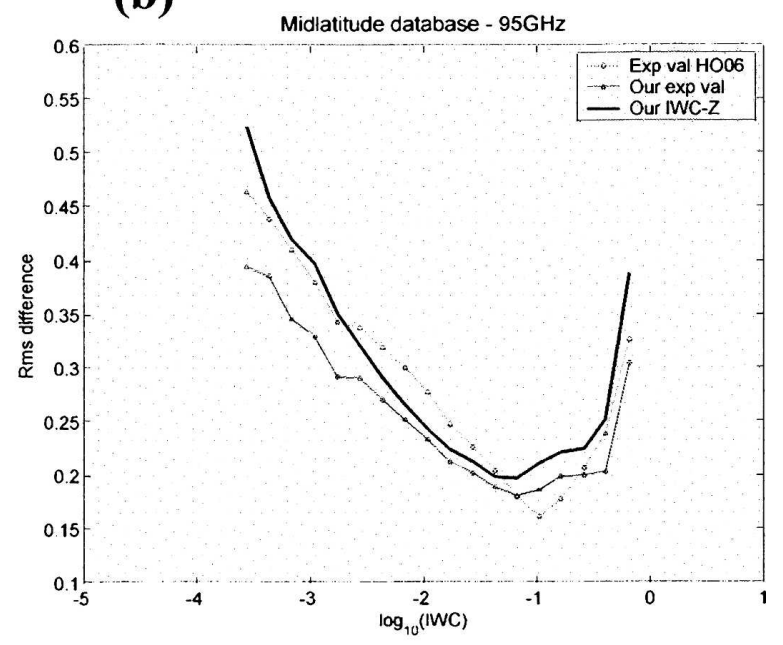

(c)

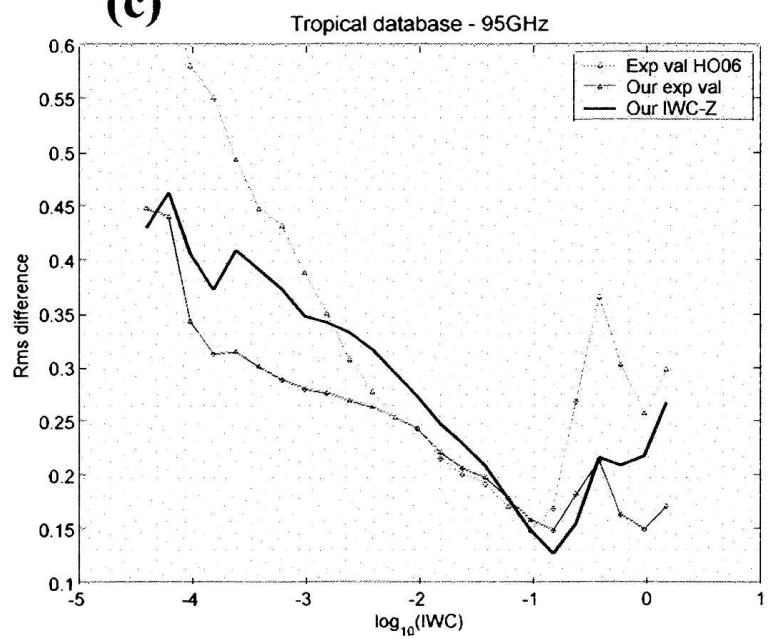

FIG. 6. Same as in Fig. 5, but at 95 GHz.

the mean bias on $\log _{10}$ (IWC) obtained with the IWC- $Z$ and IWC- $Z-T$ relationships at 35 and $95 \mathrm{GHz}$ derived in this paper. As seen in this figure, the IWC- $Z$ and IWC $-Z-T$ relationships are both characterized by a positive bias for the small IWCs and a negative bias for the large IWCs. It is observed, however, that this bias is greatly reduced when using the IWC $-Z-T$ relationships-roughly by a factor of $2(30 \%$ and $15 \%-$ $20 \%$ at 35 and $95 \mathrm{GHz}$ for IWC $=10^{-2} \mathrm{~g} \mathrm{~m}^{-3}$, respectively; $-30 \%$ and $-40 \%$ at 35 and $95 \mathrm{GHz}$ for IWC $=$ $\left.1 \mathrm{~g} \mathrm{~m}^{-3}\right)$.

\section{Further assessment of the performances of the IWC-Z and IWC-Z-T relationships}

The errors arising from the use of IWC- $Z$ and IWC$Z-T$ methods have been analyzed in the two previous sections. In this section, we attempt to quantify the ac- curacy of these methods by statistically comparing the retrieved IWCs with those derived from a more elaborate radar-lidar retrieval method developed and validated recently (denoted as the Rali method in what follows; Tinel et al. 2005), which makes use of radar reflectivity and lidar apparent backscatter for the IWC retrieval. In the version we use in this paper, an improvement has been brought to the original version of Tinel et al. (2005) by including a correction for multiple scattering in the lidar backscatter coefficient, which has proven to have a significant impact on the retrieval (Hogan et al. 2006b). The IWC estimate from Rali is assumed to be accurate to within $20 \%-30 \%$ (as in this paper though, this error does not include the possible error arising from the ice particle density). It is therefore a good reference for the evaluation of the IWC retrieval from the IWC- $Z$ and $I W C-Z-T$ relationships. 


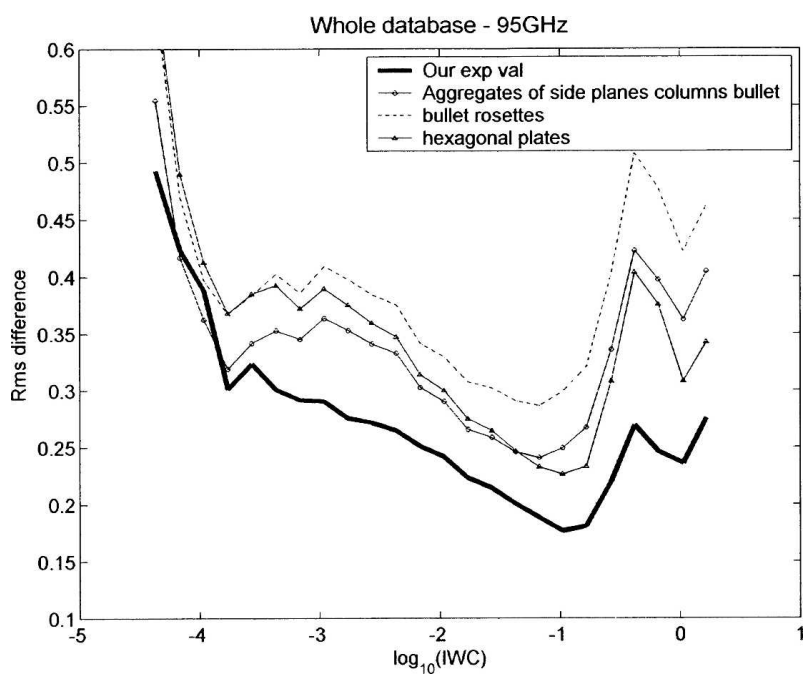

FIG. 7. Rms difference for the whole database between the $\log (\mathrm{IWC})$ computed at $95 \mathrm{GHz}$ from the IWC-Z-T expectedvalue relationships derived in this study and the $\log$ (IWC) computed directly from the true particle size distributions and four different mass-dimension assumptions: the Brown and Francis (1995) aggregates (thick solid line, identical to the solid line with circles in Fig. 6a), the aggregates of side planes/columns/bullets (solid line with circle), the bullet rosettes (dashed line), and the hexagonal plates (solid line with triangles).

To perform this evaluation, $2 \mathrm{yr}$ of vertically pointing ground-based Doppler cloud radar observations over three European sites (Chilbolton, United Kingdom; Palaiseau; and Cabauw, Netherlands) have been used. This database has been collected in the framework of the European CloudNET project (Illingworth et al. 2007). Because of the fact that the lidar signal is completely extinguished for optical depths of around 3 (and even less for the lidar ceilometers at Chilbolton and Cabauw), the comparison is naturally restricted mostly to thin ice clouds and lower parts of thicker ice clouds. As discussed in the introduction, this is a major advantage of radar-only methods such as IWC $-Z$ or IWC$Z-T$ relationships, from which the whole cloud depth can be explored. The comparison of the IWC retrieved using the Rali method and the IWC-Z/IWC- $Z-T$ relationships is shown for the Palaiseau dataset $(95-\mathrm{GHz}$ radar) in Figs. 9a and 9b, respectively, as a density of points over which the bias and standard deviation of the error in each IWC bin are superimposed. Figure 9c shows the rms differences as was done with the in situ microphysical database. The first striking result is the large scatter around the 1:1 line for both methods, indirectly reflecting the large natural variability of IWC for a given reflectivity, which translates directly into differences with the Rali method that does not make use of a unique relationship between IWC and $Z$. Rms differences (Fig. 9c) are around 0.8 with IWC- $Z$ (0.65 with IWC-Z-T) for IWC $=10^{-3} \mathrm{~g} \mathrm{~m}^{-3}$, decreasing roughly linearly down to $0.28(+90 \% /-48 \%$ fractional error) for IWC $-Z$, and 0.35 for IWC $-Z-T(+125 \% /$ $-55 \%$ fractional error) for IWC $=10^{-1} \mathrm{~g} \mathrm{~m}^{-3}$. These rms difference values translate into large fractional errors for the small IWCs, which is probably due to the small amount of points for comparisons with Rali for $\log _{10}($ IWC $)<-2.5$, as shown in Fig. 9d. For the mean difference over the IWC range, it is found that the IWC- $Z-T$ relationships provide a much smaller bias than the IWC $-Z$ relationships for the IWCs less than $10^{-2} \mathrm{~g} \mathrm{~m}^{-3}$ (a $40 \%-50 \%$ overestimation with respect to the radar-lidar retrievals, as compared with $200 \%$ overestimation for IWC $=10^{-3} \mathrm{~g} \mathrm{~m}^{-3}$ ), whereas both types of relationships have similar performances for IWC > $10^{-2} \mathrm{~g} \mathrm{~m}^{-3}$ (a $20 \%-40 \%$ systematic overestimation with respect to the radar-lidar retrievals). The radar at Palaiseau is at $95 \mathrm{GHz}$. If we compare the systematic positive bias of the IWC- $Z-T$ relationships with respect to the radar-lidar retrievals over the whole IWC range (Fig. 9b) with the biases obtained with the in situ particle size distribution estimates in Fig. 8b, then the positive bias for the small IWCs (IWC $<10-2 \mathrm{~g} \mathrm{~m}^{-3}$ ) with respect to the radar-lidar retrievals is clearly attributable to the IWC $-Z-T$ relationships, because roughly the same overestimation is found $(40 \%$ with respect to radar-lidar, $20 \%$ with respect to in situ-derived IWCs). For large IWCs though, the IWC- $Z-T$ relationships tend to underestimate IWC by $40 \%$ according to the in situ aircraft data, whereas it tends to produce IWCs larger than the radar-lidar retrievals. This result is likely due to the fact that the Mie effect is not accounted for in the radar-lidar retrievals, whereas it is partly included implicitly in the derivation of the IWC $-Z$ and IWC $-Z-T$ relationships. As a result, the IWC $-Z-T$ relationships seem to produce less negative bias than do the radar-lidar retrievals for the large IWCs.

\section{Conclusions}

The objective of this paper was to assess the performances of the IWC- $Z$ and IWC- $Z-T$ methods for accurate retrievals of IWC from radar in space or at ground-based sites, in the framework of the forthcoming CloudSat spaceborne radar, and of the European CloudNET (Illingworth et al. 2007) and U.S. ARM projects. For this purpose we have used a large airborne in situ microphysical database to perform a detailed error analysis of the IWC- $Z$ and IWC- $Z-T$ relationships. The error analysis discussed here does not include the effect of small ice particles not sampled by the 2D sensors or the errors arising from the use of a massdimension assumption. These sources of errors have nevertheless been bounded: the small ice particles are 

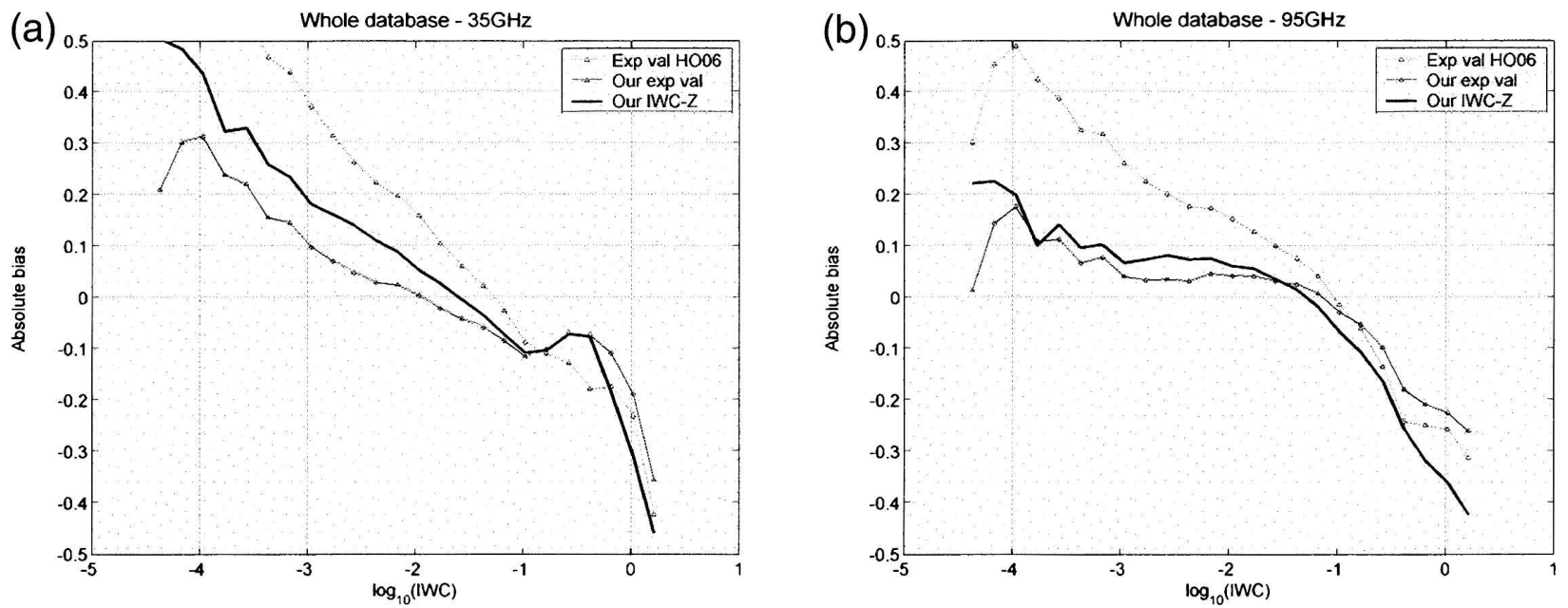

FIG. 8. Mean difference between the $\log$ (IWC) computed from the true particle size distributions and a mass-dimension assumption (the reference) and the $\log$ (IWC) computed at (a) 35 and (b) $95 \mathrm{GHz}$ from the IWC- $Z-T$ expected-value relationships of HO06 (dotted line with circles), from the IWC- $Z-T$ expected-value relationships (thin solid line with circles) and the IWC- $Z$ relationships (thick solid lines) derived in this study using the whole database.

found to contribute to around $5 \%-15 \%$ to the total IWC, and the use of a wrong mass-dimension relationship results in a roughly constant increase by $0.05-0.1$ of the rms errors, depending on the ice crystal density considered.

The IWC- $Z$ relationships have been first evaluated at two common radar frequencies for cloud physics-35 and $95 \mathrm{GHz}$. This study shows that the use of a single IWC- $Z$ relationship to estimate IWC at global scale would be feasible up to $-15 \mathrm{~dB} Z$, but for larger reflectivities different sets of relationships must be used for midlatitude and tropical ice clouds, probably owing to different formation mechanisms (mostly convectively generated in the Tropics and synoptically generated at midlatitudes).

New IWC $-Z$ and IWC- $Z-T$ relationships have then been derived from the large aircraft database. The error analysis for the IWC- $Z$ relationships shows that the IWC $-Z$ relationships produced maximum errors for small IWCs, decreasing roughly linearly from $+300 \%$ / $-75 \%$ at $35 \mathrm{GHz}$ and $+210 \% /-70 \%$ at $95 \mathrm{GHz}$ for IWC $=10^{-4} \mathrm{~g} \mathrm{~m}^{-3}$ to $+75 \% /-45 \%$ for IWC $=10^{-2} \mathrm{~g}$ $\mathrm{m}^{-3}$. The minimum errors of around $+50 \% /-33 \%$ are obtained for the intermediate IWCs (from IWC = $0.03-1 \mathrm{~g} \mathrm{~m}^{-3}$ ) at the two radar frequencies. Then, for the large IWCs the errors linearly increase from $+50 \%$ / $-33 \%$ at IWC $=1 \mathrm{~g} \mathrm{~m}^{-3}$ to $+210 \% /-70 \%$ at $35 \mathrm{GHz}$ and $+160 \% /-60 \%$ at $95 \mathrm{GHz}$ for the largest IWCs.

The same analysis conducted using the IWC $-Z-T$ relationships shows that the shape of the error curves as a function of IWC is similar in all cases to the shape of the error curve for the IWC- $Z$ relationships, with a general reduction of the error magnitudes. Errors are maximum for small IWCs, as was the case with the IWC $-Z$ relationships, decreasing roughly linearly from $+190 \% /-65 \%$ at $35 \mathrm{GHz}(+150 \% /-60 \%$ at $95 \mathrm{GHz})$ for IWC $=10^{-4} \mathrm{~g} \mathrm{~m}^{-3}$ to $+70 \% /-40 \%$ for IWC $=10^{-2}$ $\mathrm{g} \mathrm{m}^{-3}$. The minimum errors of around $+50 \% /-33 \%$ are obtained for the intermediate IWCs (IWC $=0.03-1$ $\mathrm{g} \mathrm{m}^{-3}$ ), with a magnitude similar to that achieved with the IWC $-Z$ relationships. Then, for the large IWCs the errors linearly increase to reach $+140 \% /-60 \%$ at 35 $\mathrm{GHz}$ and $+100 \% /-50 \%$ at $95 \mathrm{GHz}$ for the largest IWCs. In all cases, the error characteristics as a function of IWC are broadly similar when the midlatitude and tropical subsets are considered instead of the whole database.

The performances of the IWC- $Z$ and IWC- $Z-T$ relationships have also been evaluated using systematic comparisons with the IWCs retrieved using a radarlidar method (Tinel et al. 2005) applied to $2 \mathrm{yr}$ of continuous ground-based radar-lidar observations in the frame of the CloudNET project. Results are comparable to the conclusions drawn from the in situ microphysical database. It is found that the IWC-Z-T relationships provide a much smaller bias than do the IWC $-Z$ relationships for the IWCs less than $10^{-2} \mathrm{~g} \mathrm{~m}^{-3}$ (a $40 \%-50 \%$ overestimation with respect to the radarlidar retrievals, as compared with the $200 \%$ overestimation produced by the IWC $-Z$ relationships for IWC $=10^{-3} \mathrm{~g} \mathrm{~m}^{-3}$ ), whereas the IWC- $Z$ and IWC$Z-T$ relationships have similar performances for IWC $>10^{-2} \mathrm{~g} \mathrm{~m}^{-3}$ (a $20 \%-40 \%$ systematic overestimation with respect to the radar-lidar retrievals). It is believed, 

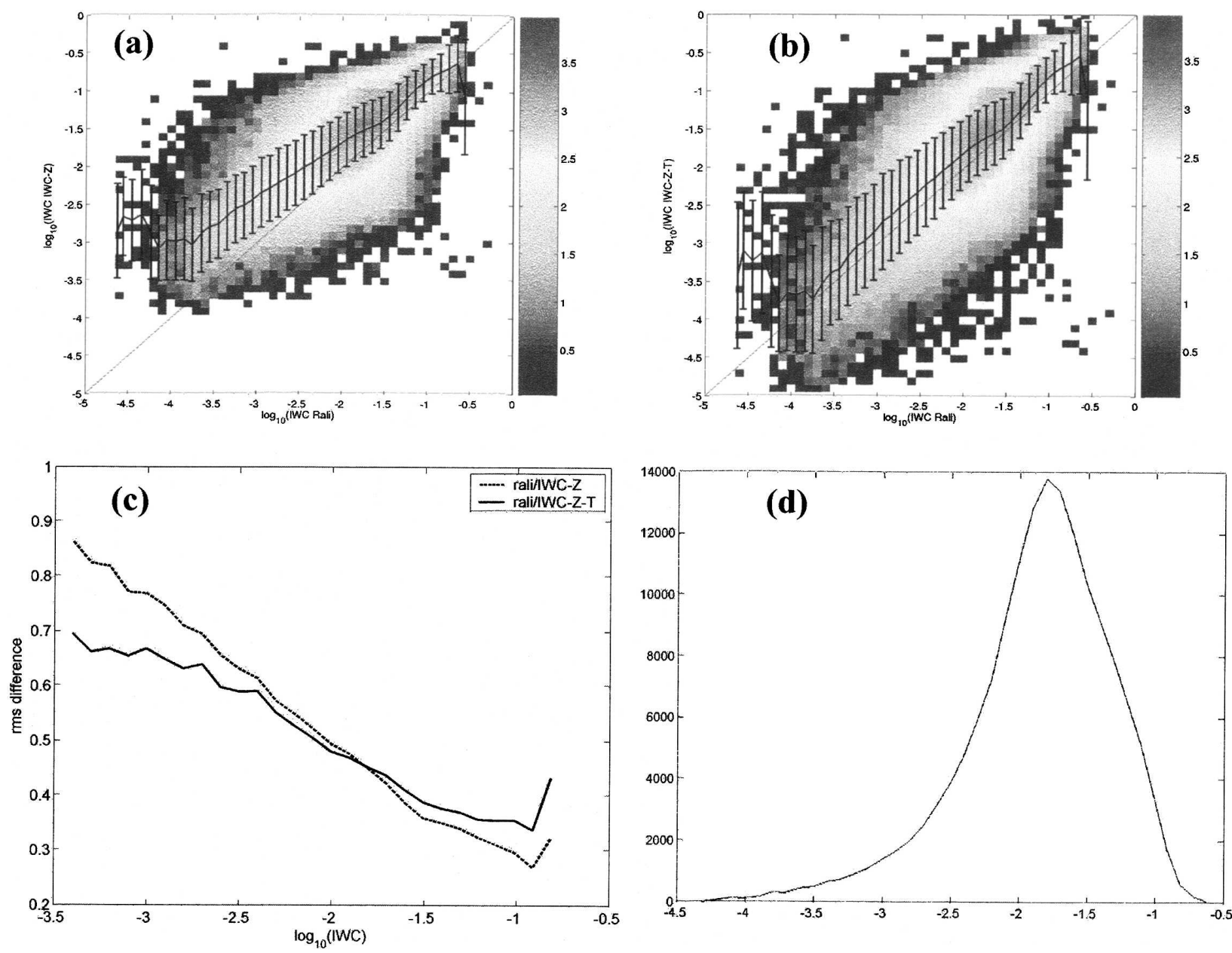

FIG. 9. Comparison between the IWCs retrieved using the modified Tinel et al. (2005) radar-lidar algorithm and (a) the IWC- $Z$ midlatitude relationships or (b) the IWC- $Z-T$ expected-value relationships, both derived in the current study. The gray shading corresponds to $\log (N)$, where $N$ is the number of points for comparison. The solid line and error bars are the mean difference and standard deviation of $\log (\mathrm{IWC})$ derived from IWC $-Z$ or IWC- $Z-T$ relationships in each IWC class. (c) Rms difference between $\log ($ IWC) derived from Rali and the $\log$ (IWC) derived from IWC- $Z$ (dotted line) or IWC-Z-T (solid line), and (d) number of points for comparison in each IWC class.

however, that errors generated by the radar-lidar retrieval are larger than those generated by the IWC$Z-T$ relationships for large IWCs, owing to the fact that the Mie effect is not accounted for in this method.

The comparison of errors associated with the IWC $-Z$ and IWC- $Z-T$ relationships in IWC classes with respect to the in situ microphysical database and radarlidar retrievals shows that the main improvement brought by the use of temperature as an additional constraint to the IWC retrieval is to reduce both the systematic overestimation and rms differences of the small IWCs (IWC $<0.01 \mathrm{~g} \mathrm{~m}^{-3}$ ). For the large IWCs, the use of temperature also results in a reduction by a factor of 2 of the systematic underestimation of the large IWCs, but it does not significantly reduce the rms differences. This latter improvement may be attributed to a better account of the Mie effect when IWC- $Z$ relationships are stratified by temperature.

Acknowledgments. This work has been funded by CNES (French Space Agency) and Alcatel in the framework of the CloudSat/Calipso radar-lidar mission and by the European Union CloudNET project under Contract EVK2-CT-2000-00065. We are also indebted to Robin Hogan from University of Reading, who provided us with processed EUCREX and CEPEX datasets and the latest version of his IWC- $Z-T$ relationships before publication.

\section{REFERENCES}

Atlas, D., S. Y. Matrosov, A. J. Heymsfield, M. D. Chou, and D. B. Wolff, 1995: Radar and radiation properties of ice clouds. J. Appl. Meteor., 34, 2329-2345. 
Babb, D. M., J. Verlinde, and B. A. Albrecht, 1999: Retrieval of cloud microphysical parameters from $94-\mathrm{GHz}$ radar Doppler power spectra. J. Atmos. Oceanic Technol., 16, 489-503.

Brown, P. R. A., and P. N. Francis, 1995: Improved measurements of the ice water content in cirrus using a total water probe. J. Atmos. Oceanic Technol., 12, 410-414.

- A. J. Illingworth, A. J. Heymsfield, G. M. McFarquhar, K. A. Browning, and M. Gosset, 1995: The role of spaceborne millimeter-wave radar in the global monitoring of ice cloud. J. Appl. Meteor., 34, 2346-2366.

Delanoë, J., A. Protat, J. Testud, D. Bouniol, A. Heymsfield, A. Bansemer, P. R. A. Brown, and R. M. Forbes, 2005: Statistical properties of the normalized ice particle size distribution. J. Geophys. Res., 110, D10201, doi:10.1029/2004JD005405.

Donovan, D. P., and A. C. A. P. van Lammeren, 2001: Cloud effective particle size and water content profile retrievals using combined lidar and radar observations, 1 , Theory and examples. J. Geophys. Res., 106, 27 425-27 448.

_- and Coauthors, 2001: Cloud effective particle size and water content profile retrievals using combined lidar and radar observations, 2, Comparison with IR radiometer and in situ measurements of ice clouds. J. Geophys. Res., 106, 27 44927464.

Gaussiat, N., H. Sauvageot, and A. J. Illingworth, 2003: Cloud liquid water and ice content retrieval by multi-wavelength radar. J. Atmos. Oceanic Technol., 20, 1264-1275.

Gayet, J. F., and Coauthors, 2002: Quantitative measurement of the microphysical and optical properties of cirrus clouds with four different in situ probes: Evidence of small ice crystals. Geophys. Res. Lett., 29, 2230, doi:10.1029/2001GL014342.

Heymsfield, A. J., and C. M. R. Platt, 1984: A parameterization of the particle size spectrum of ice clouds in terms of the ambient temperature and the ice water content. J. Atmos. Sci., 41, 846-855.

Heymsfield, A., A. Bansemer, C. Schmitt, C. Twohy, and M. R. Poellot, 2004: Effective ice particle densities derived from aircraft data. J. Atmos. Sci., 61, 982-1003.

Hogan, R. J., and A. J. Illingworth, 1999: The potential of spaceborne dual-wavelength radar to make global measurements of cirrus clouds. J. Atmos. Oceanic Technol., 16, 518-531.

$\ldots$, and 2003: Parameterizing ice cloud inhomogeneity and the overlap of inhomogeneities using cloud radar data. $J$. Atmos. Sci., 60, 756-767.

— M. P. Mittermaier, and A. J. Illingworth, 2006a: The retrieval of ice water content from radar reflectivity factor and temperature and its use in evaluating a mesoscale model. $J$. Appl. Meteor., 45, 301-317.

— D. P. Donovan, C. Tinel, M. E. Brooks, D. Bouniol, A. J. Illingworth, and J. P. V. Poiares Baptista, 2006b: Independent evaluation of the ability of spaceborne radar and lidar to retrieve the microphysical and radiative properties of ice clouds. J. Atmos. Oceanic Technol., 23, 211-227.

Illingworth, A. J., and the CloudNET Team, 2007: CloudNETContinuous evaluation of cloud profiles in seven operational models using ground-based observations. Bull. Amer. Meteor. Soc., in press.

Intrieri, J. M., G. L. Stephens, W. L. Eberhard, and T. Uttal, 1993: A method for determining cirrus cloud particle sizes using lidar and radar backscatter technique. J. Appl. Meteor., 32, 1074-1082.

Janiskova, M., J.-F. Mahfouf, and J. J. Morcrette, 2002: Prelimi- nary studies on the variational assimilation of cloud-radiation observations. Quart. J. Roy. Meteor. Soc., 128, 2713-2736.

Liao, L., and K. Sassen, 1994: Investigation of relationships between Ka-band radar reflectivity and ice and water content. Atmos. Res., 34, 231-248.

Liou, K. N., 1986: Influence of cirrus clouds on weather and climate processes: A global perspective. Mon. Wea. Rev., 114, $1167-1199$.

Liu, C. L., and A. J. Illingworth, 2000: Toward more accurate retrievals of ice water content from radar measurements of clouds. J. Appl. Meteor., 39, 1130-1146.

Locatelli, J. D., and P. V. Hobbs, 1974: Fall speed and masses of solid precipitation particles. J. Geophys. Res., 79, 2185-2197.

Mace, G. G., T. P. Ackerman, P. Minnis, and D. F. Young, 1998: Cirrus layer microphysical properties derived from surfacebased millimeter radar and infrared interferometer. J. Geophys. Res., 103, 23 207-23 216.

Matrosov, S. Y., 1997: Variability of microphysical parameters in high-altitude ice clouds: Results of the remote sensing method. J. Appl. Meteor., 36, 633-648.

_ 1999: Retrievals of vertical profiles of ice cloud microphysics from radar and IR measurements using tuned regressions between reflectivity and cloud parameters. J. Geophys. Res., 104, 741-753.

_ A. V. Korolev, and A. J. Heymsfield, 2002: Profiling cloud ice mass and particle characteristic size from Doppler radar measurements. J. Atmos. Oceanic Technol., 19, 1003-1018.

Oguchi, T., 1983: Electromagnetic wave propagation and scattering in rain and other hydrometeors. Proc. IEEE, 71, 10291078 .

Protat, A., J. Delanoe, D. Bouniol, and M. Haeffelin, 2004: Dynamical, microphysical, and radiative properties of ice clouds using Doppler cloud radar measurements. Proc. Third European Conf. on Radar Meteorology, Visby, Sweden, Copernicus GmbH, 74-79.

Ramanathan, V., R. D. Cess, E. F. Harrison, P. Minnis, B. R. Barkstrom, E. Ahmad, and D. Hartman, 1989: Cloud-radiative forcing and climate: Results from the Earth Radiation Budget Experiment. Science, 243, 57-63.

Sekelsky, S. M., W. L. Eclund, J. M. Firda, K. S. Gage, and R. E. McIntosh, 1999: Particle size estimation in ice-phase clouds using multi-frequency radar reflectivity measurements at 95 , 33, and $2.8 \mathrm{GHz}$. J. Appl. Meteor., 38, 5-28.

Shcherbakov, V., J.-F. Gayet, O. Jourdan, A. Minikin, J. Ström, and A. Petzold, 2005: Assessment of cirrus cloud optical and microphysical data reliability by applying statistical procedures. J. Atmos. Oceanic Technol., 22, 409-420.

Stephens, G. L., S.-C. Tsay, P. W. Stackhouse, and P. J. Flatau, 1990: The relevance of the microphysical and radiative properties of cirrus clouds to climate and climatic feedback. $J$. Atmos. Sci., 47, 1742-1754.

- and Coauthors, 2002: The CLOUDSAT mission and the A-Train. Bull. Amer. Meteor. Soc., 83, 1771-1790.

Tinel, C., J. Testud, J. Pelon, R. H. Hogan, A. Protat, J. Delanoë, and D. Bouniol, 2005: The retrieval of ice cloud properties from cloud radar and lidar synergy. J. Appl. Meteor., 44, 860875.

Wang, Z., and K. Sassen, 2002: Cirrus cloud microphysical property retrieval using radar and lidar measurement. Part I: Algorithm description and comparison with in situ data. J. Appl. Meteor., 41, 218-229. 